Ind. Health, 1968, 6, 80 .

\title{
EFFECTS OF OXIDES OF SULPHUR ON THIN METAL FILMS
}

\author{
Katsunori HOMMA and Hiroyuki SAKABE \\ National Institute of Industrial Health, Kizuki-Sumiyoshi, Kawasaki
}

(Received June 10, 1968)

\begin{abstract}
Effects of sulphur dioxide gas, mists of aqueous sulphur dioxide and of sulphuric acid solution and silica gel particles exposed to sulphur dioxide and to sulphuric acid solution on the metal film were studied electronmicroscopically. Mists of aqueous solution of sulphur dioxide and sulphuric acid showed very similar but a little different figures. Sulphur dioxide and particles, absorbing sulphur dioxide or sulphuric acid, showed a corrosive effect on the metals with or after the exposure to high humidity.

It was emphasized that the biological effects of these pollutants should be considered together with air humidity.
\end{abstract}

For the determination of acid mist size, Hayashi, Koshi, and Sakabe1) devised a method using slide glass coated with thin metal films. By this method the original size of acid mists collected on metal films could be calculated from the size of holes formed by those mists on them. Sakabe2) introduced this method to the study of particulate air pollutants, and found that particulate matters emitted from the industrial combine comprising oil refineries and power stations were of very specific properties. Electronmicroscopic observation on the particles collected on thin films of various metals seems to be useful for the study of physicochemical natures of air pollutants. In this paper we have studied the effect of $\mathrm{SO}_{2}$ gas, mist of sulphuric acid solution and mist of water saturated with $\mathrm{SO}_{2}$ on the thin metal films.

\section{EXPERIMENTALS}

\section{Preparation of thin metal films}

Silver, copper and zinc were used as metals.

a) Preparation of silver and copper films. Specimen grid for electronmicroscope was covered by collodion as usual. This collodion membrane was placed on a slide glass and coated with fume evaporated from metals heated in tungsten wire coil in the vacuum evaporator (Hitachi Mnf. Co. HUS-3 type). The thickness of this metal films on the collodion membrane was assumed to be about $50 \sim 100 \AA$.

b) Preparation of zinc films. Zinc film could not be formed on the collodion membrane by the same method as described above. It was possible only on the other metal films covering collodion membrane. Gold was used as under- 


\section{OXIDES OF SULPHUR ON THIN METAL FILMS}

laid membrane in this study.

All these metal films were stored in a desiccator in a cold dark place.

\section{Preparation of aqueous solutions of oxides of sulphur}

a) Sulphur dioxide. Pure $\mathrm{SO}_{2}$ in cylinder was used.

b) Aqueous sulphur dioxide solution. Sulphur dioxide was bubbled through the distilled water in a flask. At first $\mathrm{SO}_{2}$ was hardly soluble in water and the most part of gas passed through the water, but it became to be solubilized gradually. In this process, the water was divided into two layers which were produced by density difference, and the boundary face rose gradually from the bottom. When this face reached the water surface $\mathrm{SO}_{2}$ became insoluble and $\mathrm{pH}$ 0.9. Since this solution was very unstable, nitrogen gas was bubbled through the solution in order to drive out $\mathrm{SO}_{2}$. After this treatment $\mathrm{pH}$ of the solution was 1.49 .

c) Sulphuric acid solution. Sulphuric acid of analysis grade was diluted with distilled water to be $\mathrm{N} / 100$ solution.

\section{Preparation of silica gel particles exposed to sulphur dioxide}

Silica gel powder of high purity having the size under 300 mesh was dried at $120^{\circ} \mathrm{C}$ for $2 \mathrm{hrs}$ and cooled in a desiccator. About $5 \mathrm{~g}$ of this dried silica gel were put into a flask and then the air in that was displaced with dried $\mathrm{SO}_{2}$. After $24 \mathrm{hrs} \mathrm{SO}_{2}$ was driven away with dried air.

\section{Preparation of silica particles exposed to sulphuric acid solution}

To $1 \mathrm{~g}$ of dried silica gel in a flask $5 \mathrm{~m} 1$ of $\mathrm{N} / 100 \mathrm{H}_{2} \mathrm{SO}_{4}$ solution were added. After shaking, water was evaporated at $120^{\circ} \mathrm{C}$, and dried particles were stored in a desiccator.

5. Sampling of the specimens on thin metal films

a) Sulphur dioxide. The humidity of one chamber was controlled by water solution saturated with sodium phosphate and that of the other was the same as the humidity in the experimental room. Relative humidity was about $98 \%$ in the former and $60 \%$ in the latter. Specimen grids covered with thin metal films were put in these two chambers in dark cool place, and $\mathrm{SO}_{2}$ was introduced in to the chambers. After a certain period, specimen grids were taken out and examined electronmicroscopically.

b) Mist of aqueous sulphur dioxide solution. Mist of aqueous $\mathrm{SO}_{2}$ solution was produced in the clean air with a nebulizer and was collected on the metal films using jet dust sampler.

c) Mist of sulphuric acid solution. This mist was prepared from N/100 aqueous 


\section{K. HOMMA AND H. SAKABE}

solution of $\mathrm{H}_{2} \mathrm{SO}_{4}$ and collected by the same method described above.

d) Silica gel particles exposed to sulphur dioxide and sulphuric acid solution.

Particles were sprinckled on the metal films, and examined electronmicroscopically. In addition to the study under usual humidity effect of high humidity was examined after these specimens were exposed to vapour from heated water.

\section{RESUlts}

\section{Effect of sulphur dioxide on metal films}

Fig. $1 \mathrm{~A}$, shows original silver film and Fig. $1 \mathrm{~B}$ and $\mathrm{C}$ exhibit the effect of $\mathrm{SO}_{2}$ on this film. There is seen the coarsening of silver particles after the exposure to $\mathrm{SO}_{2}$ even in $60 \%$ humidity. Exposure in $98 \%$ humidity produced a remarkable coarsening of particles with various densities. These were also seen in zinc film.

\section{Effects of aqueous sulphur dioxide and sulphuric acid solution}

Fig. $2 \mathrm{~A}$, shows the mist of aqueous $\mathrm{SO}_{2}$ solution and Fig. $2 \mathrm{~B}$ that of sulphuric acid sulution collected on the collodion membrane. Both mists show very similar sherical form but not the same. There can be seen the light ring around the mist of aqueous $\mathrm{SO}_{2}$ solution. Fig. $3 \mathrm{~A}, \mathrm{~B}$ show these two mists collected on the silver film. Coarsening of silver particles is seen in these pictures, and crystal like particles are observed in sulphuric acid solution, though flaky particles in aqueous $\mathrm{SO}_{2}$ solution. The former is assumed to be silver sulphate. On zinc film as seen in Fig. $4 \mathrm{~A}, \mathrm{~B}$, there two sorts of mists exhibit similar but a little different figures.

\section{Effect of silica gel particles exposed to $\mathrm{SO}_{2}$ and $\mathrm{H}_{2} \mathrm{SO}_{4}$ solution}

Fig. $5 \mathrm{~A}, \mathrm{~B}$, show the effect of particles exposed to $\mathrm{SO}_{2}$ on silver film. These particles had no effect on silver film in usual room humidity, but they showed a remarkable effect after the vapour treatment. As seen in Fig. 5 B, fine silver particles around the deposited silica powder dissolved and formed a halo with coares particles in their peripheral parts. These coarse particles were assumed to be sulphur compound of silver. Quite similar morphological patterns were also observed in silica gel exposed to $\mathrm{H}_{2} \mathrm{SO}_{4}$ solution as shown in Fig. 6.

On the copper, silica gel exposed to $\mathrm{SO}_{2}$ had no effect on the film in usual room humidity, but after the exposure to vapour, it showed a very peculiar figure that is dark halos around particles and holes like worm-eaten spots in them. These are shown in Fig. 7.

Such figure was also observed in silica gel exposed to $\mathrm{H}_{2} \mathrm{SO}_{4}$ solution. 

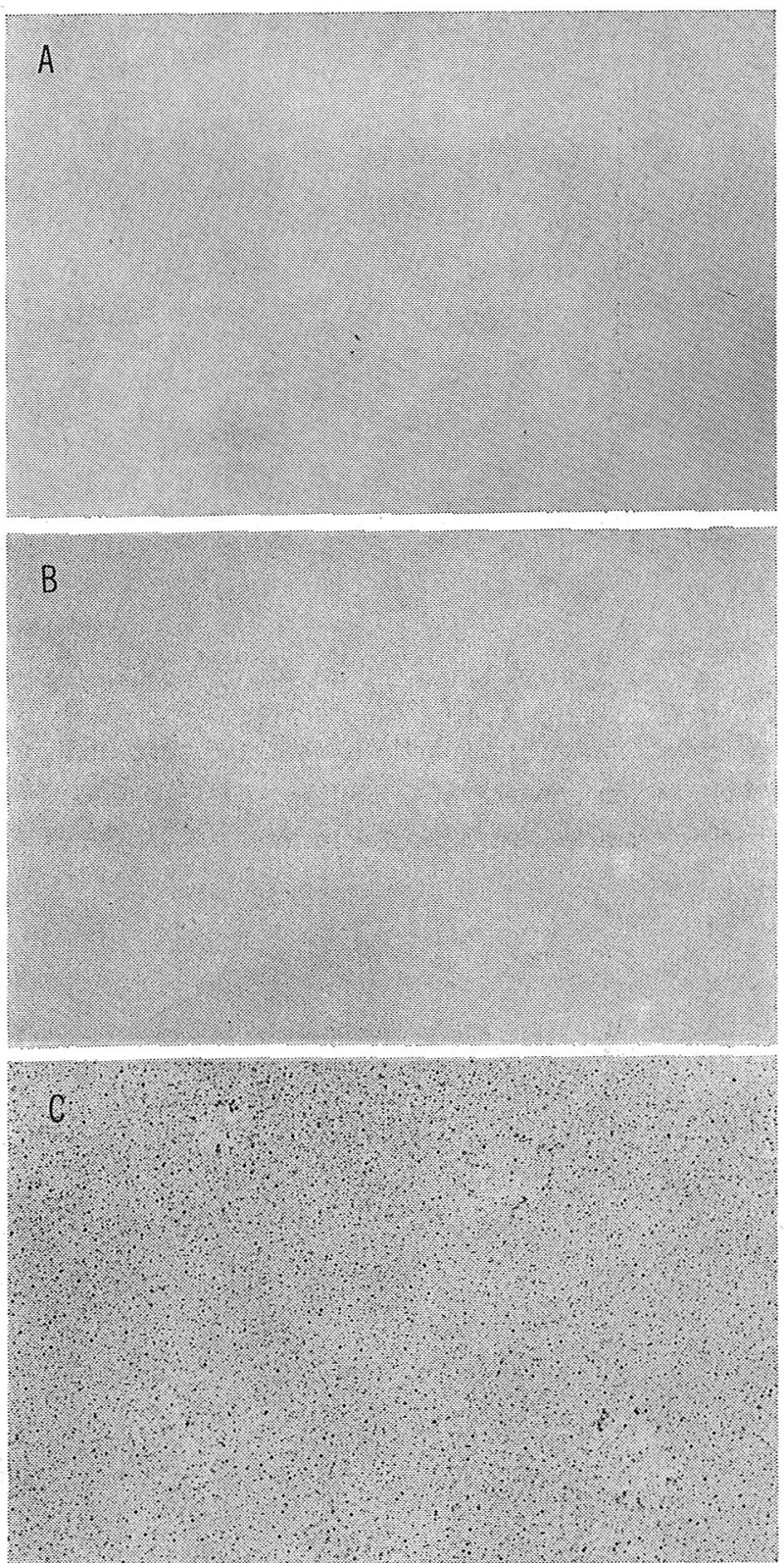

Fig. 1. Electronmicrographs of thin films made of silver.

A: without exposure to $\mathrm{SO}_{2}$ gas

B: exposed to $\mathrm{SO}_{2}$ gas in $60 \%$ humidity

C: exposed to $\mathrm{SO}_{2}$ gas in $98 \%$ humidity 


\section{K. HOMMA AND H. SAKABE}

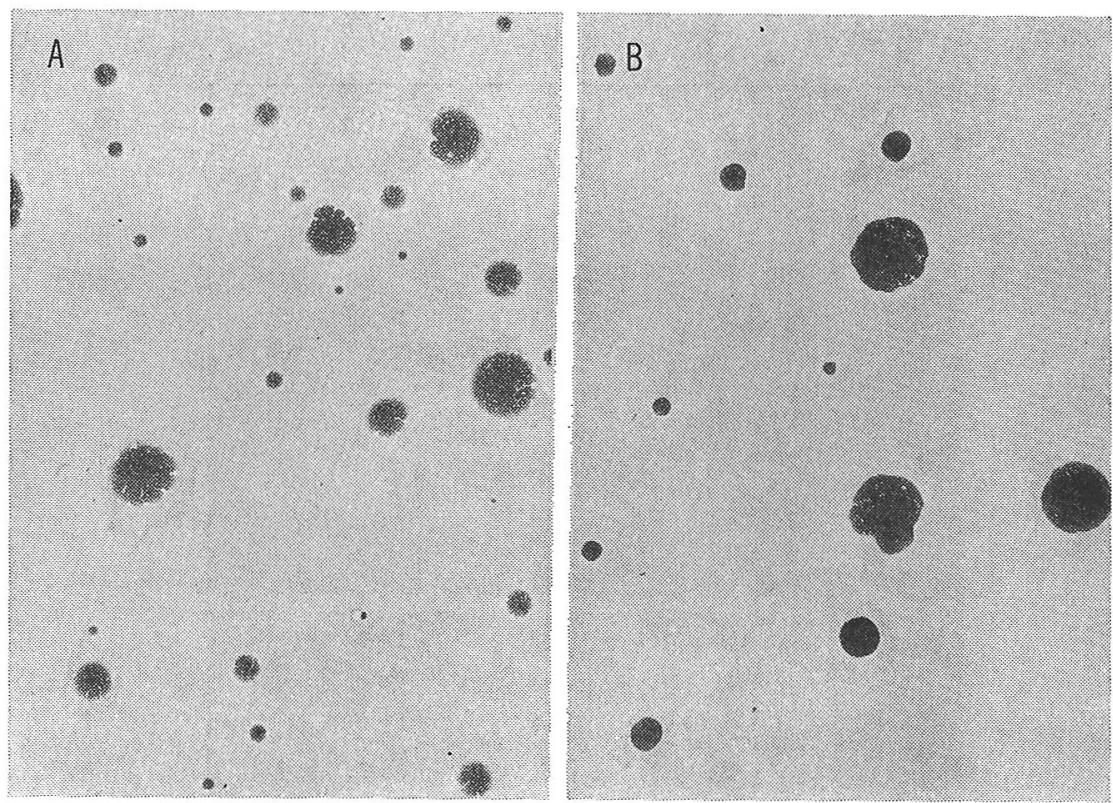

Fig. 2. Electronmicrographs of mist particles collected on collodion membrans.

A: preparing from aqueous $\mathrm{SO}_{2}$ solution

B: preparing from sulphuric acid solution
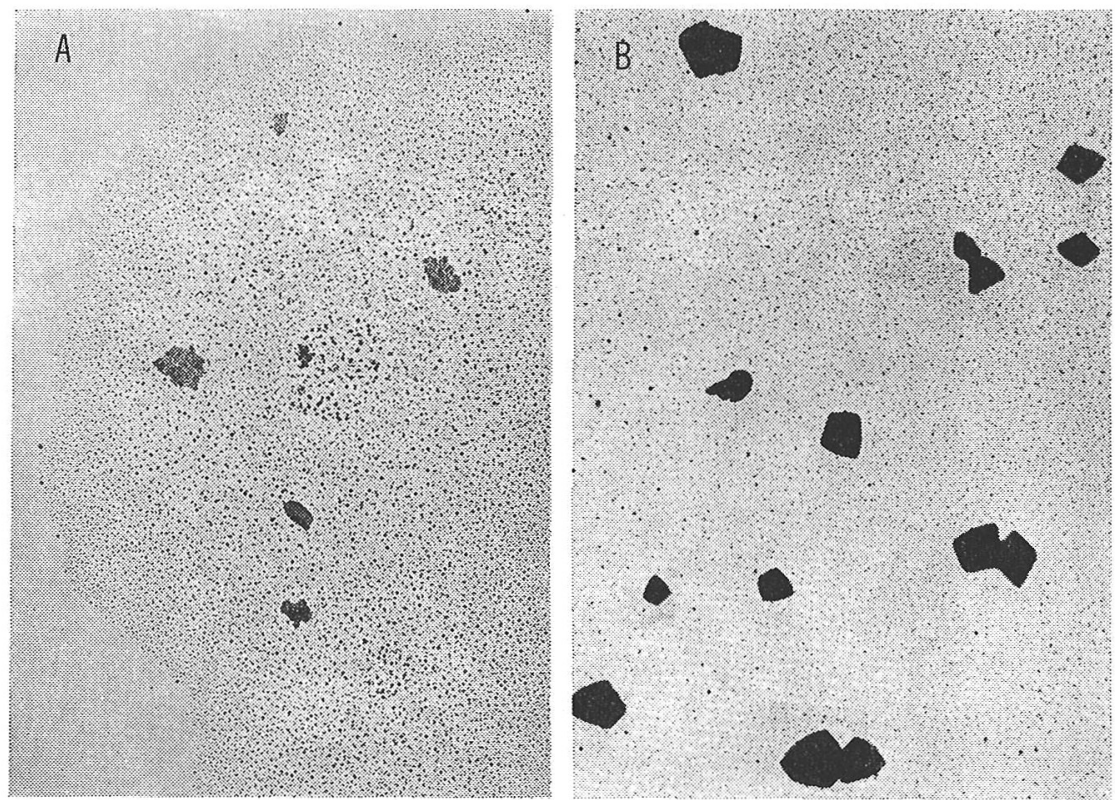

Fig. 3. Electronmicrographs of thin silver films by coarsened with collecting of two kind mists.

A: from aqueous $\mathrm{SO}_{2}$ solution

$B$ : from sulphuric acid solution 
OXIDES OF SULPHUR ON THIN METAL FILMS
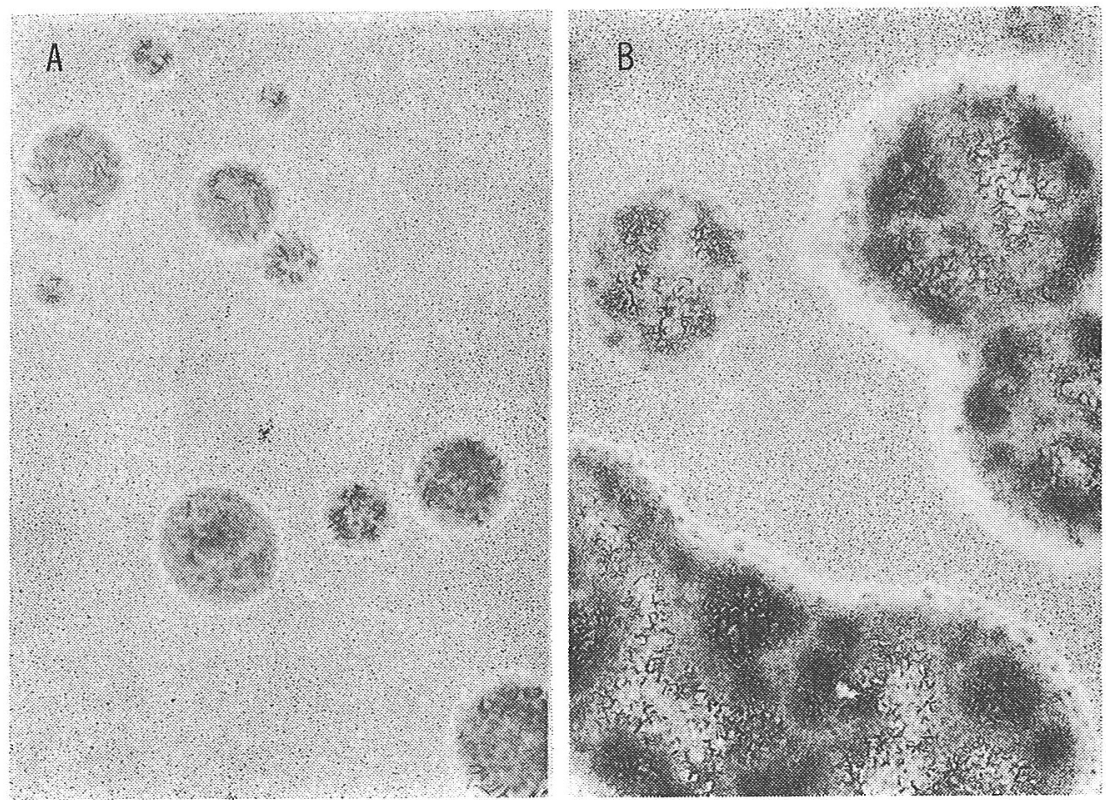

Fig. 4. Electronmicrographs of thin zinc films by coarsened with collecting of two kind mists.

A: prepared from aqueous $\mathrm{SO}_{2}$ solution

B : prepared from sulphuric acid
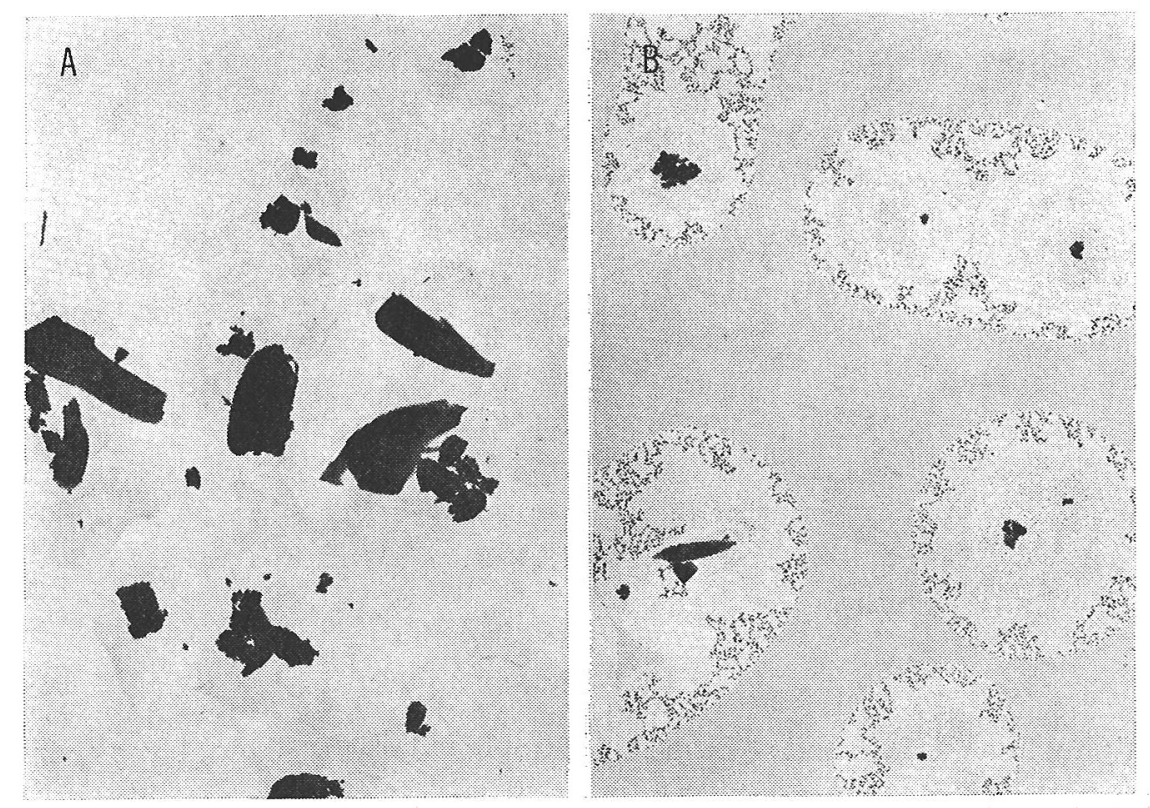

Fig. 5. Electronmicrographs of thin silver films on which silica gel particles exposed to $\mathrm{SO}_{2}$ gas were sprinkled.

A : The treated film placed in a room with about $60 \%$ humidity during 24 hours

B : The treated film exposed to water vapour in a moment 


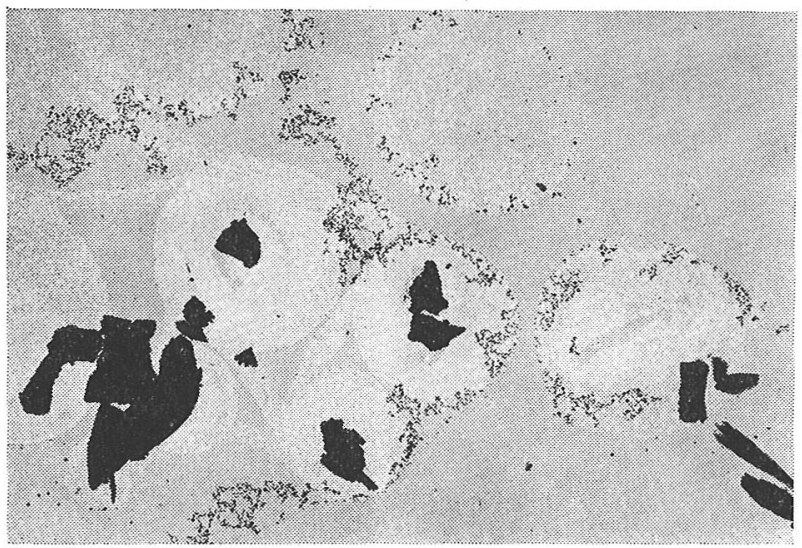

Fig. 6. Electronmicrograph of thin silver film on which silica gel particles exposed to $\mathrm{H}_{2} \mathrm{SO}_{4}$ solution were sprinkled and afterwards treated with water vapour.

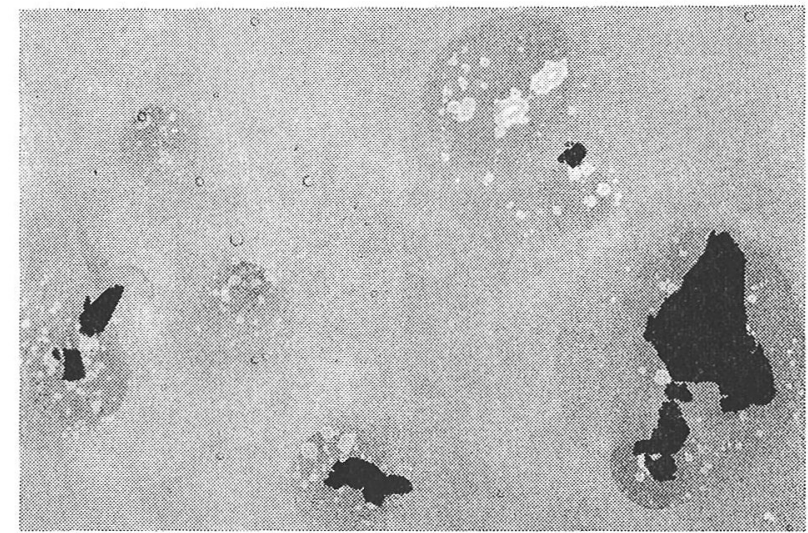

Fig. 7. Electronmicrograph of thin copper film on which silica gel particles exposed to $\mathrm{SO}_{2}$ gas were sprinkled and afterwards treated with water vapour.

\section{Discussion}

1. Sulphuric acid mist and aqueous sulphur dioxide mist showed very similar but a little different figures when they were collected on collodion, silver, copper, and zinc films. This slight morphological difference was assumed to be due to the chemical difference of these two kinds of mist. In the former, ion acting upon metals was assumed to be $\mathrm{HSO}_{3}{ }^{-}$or $\mathrm{HS}_{2} \mathrm{O}_{5}{ }^{-}$and in the latter $\left.\mathrm{HSO}_{4}^{-}, 3\right)$ 


\section{OXIDES OF SULPHUR ON THIN METAL FILMS}

2. Sulphur dioxide gas and silica gel particles which adsorbed $\mathrm{SO}_{2}$ were almost inert to silver, copper and zinc films in ordinary humidity, but they became very corrosive to these metals in high humidity. This fact suggests that we should be very careful to the humidity effect when we consider the effect of $\mathrm{SO}_{2}$.

It is well known that air pollution with dense fog is very dangerous to the health of inhabitants. Gases such as $\mathrm{SO}_{2}$ or $\mathrm{NO}_{2}{ }^{4)}$ were assumed to become very reactive in city air of high humidity by producing new toxic compounds with other pollutants as shown in this study. Many hygroscopic gases can not penetrate into the deep part of lung air way but the particles of about $1 \mu$ size can reach the alveoli and deposit there. Therefore, the particulate air pollutants adsorbing oxides of sulphur or nitrogen could produce severe reaction in the deeper part of the lung by virtue of high humidity in the air way or water at the deposited site.

\section{REFERENCES}

1) Hayashi, H., Koshi, S. and Sakabe, H. (1961). Bull. Nat. Inst. Ind. Health, No. 6, 35.

2) Sakabe, H. (1964). Proc. Roy. Soc. Med., 57, 1005.

3) Schroeter, L. C. (1966). Sulfur dioxide, p. 13. Pergamon Press, Oxford.

4) Sakabe, H., Homma, K., Arito, H., Matsumura, Y., Hara, H. and Soda, R. (1967). Ind. Health, 5, 293. 